Further Engineering Dynamics 
Also from Macmillan Education

An Introduction to Engineering Fluid Mechanics, Second Edition J. A. Fox

Basic Engineering Mechanics

J. H. Hughes and K. F. Martin

Introduction to Control Theory

S. A. Marshall

Mechanics of Machines

G. H. Ryder and M. D. Bennett 


\section{Further Engineering Dynamics}

\section{J. C. Maltbaek}

Senior Lecturer,

Department of Engineering Science,

University of Exeter 
(C) J. C. Maltbaek 1980

All rights reserved. No part of this publication may be reproduced or transmitted, in any form or by any means, without permission.

First published 1980 by

THE MACMILLAN PRESS LTD

London and Basingstoke

Associated companies in Delhi Dublin

Hong Kong Johannesburg Lagos Melbourne

New York Singapore and Tokyo

\section{British Library Cataloguing in Publication Data}

Maltbaek, Jorgen C

Further engineering dynamics.

1. Dynamics

I. Title

$620.1^{\prime} 04$

TA352

ISBN 978-0-333-24531-6 ISBN 978-1-349-16321-2 (eBook)

DOI 10.1007/978-1-349-16321-2

This book is sold subject to the standard conditions of the Net Book Agreement.

The paperback edition of this book is sold subject to the condition that it shall not, by way of trade or otherwise, be lent, resold, hired out, or otherwise circulated without the publisher's prior consent in any form of binding or cover other than that in which it is published and without a similar condition including this condition being imposed on the subsequent purchaser. 
To Kirsten, Peter and Christian 


\section{Contents}

$\begin{array}{ll}\text { Preface ix } & \text { ix }\end{array}$

1 Dynamics of a System of Particles 1

1.1 Equations of Motion 1

1.2 Impulse and Momentum 5

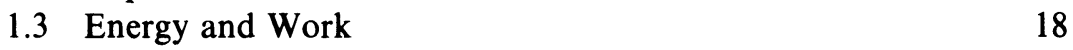

Problems $\quad 24$

2 Systems with Variable Mass 28

2.1 Equation of Motion for a System with Variable Mass 28

2.2 Systems with Total Mass Increasing with Time 29

2.3 Systems with Total Mass Decreasing with Time 31

Problems $\quad 34$

3 Lagrange's Equations for Systems with Constraints Depending on Time, and Impulsive Motion

3.1 Some Important Concepts and Definitions in Lagrangian Dynamics

3.2 Some Useful Relationships for Partial and Time Derivatives of a Function of Several Variables

3.3 Development of Lagrange's Equations 44

3.4 Lagrange's Equations for Impulsive Motion 53

Problems $\quad 59$

4 Vibrations with Two Degrees of Freedom 62

4.1 Free Vibrations without Damping 63

4.2 Free Vibrations with Viscous Damping 69

4.3 Forced Vibrations without Damping 74

4.4 Forced Vibrations with Viscous Damping 76

4.5 The Undamped Dynamic Vibration Absorber 79

Problems $\quad 84$ 
5 Rotation about a Fixed Point-Gyroscopic Motion 89

5.1 Kinematics of Rotation about a Fixed Point 89

5.2 Dynamics of a Rigid Body Rotating about a Fixed Point 95 Problems

6 Gyroscopic Effects in Machinery

6.1 Gyroscopic Effects in Rolling Mills 112

6.2 Gyroscopic Effects of Turbines and Dynamos in Ships 114

6.3 Gyroscopic Effects in Locomotive Wheels Rounding a Curve 116

6.4 Gyroscopic Effects in Aircraft 117 Problems

7 Some Applications of Gyroscopes 121

$\begin{array}{lll}7.1 & \text { Rate Gyroscope } & 121\end{array}$

7.2 The Gyroscope as Direction Indicator 123

7.3 The Gyroscopic Compass 124

$\begin{array}{lll}7.4 \text { Monorail Stabilisation } & 126\end{array}$ $\begin{array}{ll}\text { Problems } & 131\end{array}$

8 Dimensional Analysis and the Theory of Models 132

8.1 Units and Dimensions 132

8.2 Dimensional Homogeneity 133

8.3 Dimensional Analysis 134

8.4 Buckingham's Pi-theorem 138

8.5 The Theory of Models 140

Problems $\quad 144$

9 An Introduction to Automatic Control 146

9.1 Introduction 146

9.2 Open-loop and Closed-loop Control Systems 147

9.3 Transfer Functions 148

9.4 A Remote Position Control System 152

$\begin{array}{ll}\text { 9.5 Derivative Control } & 154\end{array}$

9.6 Routh's Criterion for Stability 157

9.7 Harmonic Response Loci 159

9.8 Nyquist's Criterion for Stability 162

9.9 Bode Diagrams-Logarithmic Plotting 165

$\begin{array}{ll}\text { Problems } & 167\end{array}$

$\begin{array}{ll}\text { Answers to Problems } & 169\end{array}$

$\begin{array}{ll}\text { Index } & 175\end{array}$ 


\section{Preface}

The rapid developments in engineering and science mean that today's engineering and science students meet new and more challenging situations in dynamics. To deal with these problems, further developments in dynamics beyond the usual courses in elementary to intermediate dynamics are increasingly necessary. It is hoped that this book will be of help on such courses for second and third-year students in any branch of engineering and physics, both at universities and polytechnics.

The book has been arranged in self-contained chapters so that they may be studied in any combination and order.

Chapter 1 deals with the dynamics of a system of particles; several examples of fluid motion are included, although the necessarily brief discussion of this subject is only intended to give a broader view of a subject which is usually treated in depth in specialised courses in fluid mechanics. Chapter 2 gives a short introduction to systems where the total mass of the system is increasing or decreasing.

In chapter 3 Lagrange's equations of motion are introduced in a general form, including constraints depending on time. Previous experience in these equations is useful but is not essential since the equations are developed from fundamental ideas. Lagrange's equations are probably the most powerful method known in engineering dynamics for the determination of the equations of motion of a dynamic system and they allow for the solution of very complex dynamic systems. The equations have been generalised to include the problems of impact and impulsive motion.

Chapter 4 introduces vibrations with two degrees of freedom and includes examples on both linear and torsional systems with and without damping.

Chapter 5 gives a general discussion of rotation about a fixed point and general gyroscopic motion. It introduces the Euler angles as generalised coordinates and the equations of motion are developed both by the Lagrangian method and by the more common Euler method; various types of special cases are considered in detail. Chapter 6 deals with gyroscopic effects in machinery and chapter 7 with the applications of gyroscopes in the fields of direction indication and stabilisation.

In chapter 8 the subject of dimensional analysis and its applications are discussed, including Buckingham's pi-theorem. The chapter ends with a discussion of the theory of models. 
The final chapter gives a short introduction to the subject of automatic control, a subject that is intimately linked with the basic subject of dynamics. Included is a discussion of transfer functions and Routh's and Nyquist's stability criteria.

The necessary background in dynamics is that which is provided in most cases in elementary to intermediate dynamics in universities and polytechnics. This part of the subject has been given extensive treatment in the author's earlier book Essential Engineering Dynamics (published by Crosby Lockwood).

The author takes the opportunity to thank his wife Kathleen for typing the original manuscript, and to express his appreciation and thanks to the publishers, especially to Malcolm Stewart, for suggestions for improvements and encouragement during the writing of the book. 